\section{pH Microsensors Allow Local Measurements of Pitting Corrosion at MnS Sites in Stainless Steel}

$\mathrm{MnS}$ inclusions in stainless steel provide initiation sites for pitting corrosion. Jung O. Park and Hans Böhni from the Institute of Materials Chemistry and Corrosion in the Swiss Federal Institute of Technology used $\mathrm{pH}$ microsensors and microelectrochemical cells to observe the transient $\mathrm{pH}$ fluctuations as well as electrical activities during the dissolution of MnS inclusions in chloride and nonchloride solutions. There is a marked deviation in both transient $\mathrm{pH}$ and electrical current density from the norm during the commencement of MnS inclusion dissolution as reported in the September issue of Electrochemical and Solid-State Letters.

AISI 304 stainless steel samples with well-isolated $\mathrm{MnS}$ inclusions were placed in $1 \mathrm{M} \mathrm{Na}_{2} \mathrm{SO}_{4}(\mathrm{pH} 5.6$ ) and $0.1 \mathrm{M}$ $\mathrm{NaCl}$ (pH 5.4) solutions. A pH microsensor, $10 \mu \mathrm{m}$ in diameter, was embedded in a capillary, $100 \mu \mathrm{m}$ in diameter. The microsensor tip was held $50 \mu \mathrm{m}$ away from the sample surface. The electrochemical cell was comprised of a Pt counter electrode and a standard calomel electrode. Potential sweeps from $-300 \mathrm{mV}$ and up were performed at a rate of $0.2 \mathrm{mV} / \mathrm{s}$ for the nonchloride solution and $0.5 \mathrm{mV} / \mathrm{s}$ for the chlorinated solution. The researchers have found that for the nonchlorinated sample, an increase in current activity was detected at $300 \mathrm{mV}$, and at the same time, its $\mathrm{pH}$ fell to a minimum of 4.1 before returning to the proper value. For the chlorinated solution, current activity increased between 380 and $520 \mathrm{mV}$, while the $\mathrm{pH}$ dropped to 2.4 at $400 \mathrm{mV}$ and fluctuated between 2 and 4.2 within the $400-520 \mathrm{mV}$ range. The researchers attributed these fluctuations in current activity as well as $\mathrm{pH}$ within the $380-400$ $\mathrm{mV}$ range to metastable pitting events due to the dissolution of MnS inclusions. The corresponding change of $\mathrm{pH}$ and electrical activity as a function of corrosion progress was clearly identified. According to the scientists, this research is capable of expanding transient and highly localized studies of corrosion events.

JunE LAU

\section{SHG Utilized as Nondestructive Method of Buried Corrosion Detection}

The use of second harmonic generation (SHG) signal as a means of corrosion detection for bodies coated with paint has been demonstrated by a group from the Departments of Physics and of Electrical
Engineering at City College of New York. While scientists desire the ability to detect the onset of corrosion underneath layers of paint, current nondestructive methods are limited. As reported in the August 15 issue of Optics Letters, such a task is made possible by the use of a focused laser in the near infrared region to map out a 2D/3D corrosion profile.

The output of a modelocked Ti:sapphire laser, with an $810 \mathrm{~nm}$ wavelength, $120 \mathrm{fs}$ pulse duration, and $76 \mathrm{MHz}$ pulse repetition rate, was used to scan the volume of a coated-uncorroded, an uncoated-corroded, and a coated-corroded sample. The incident optical beam is focused with a $20 \mathrm{X}$ lens (Numerical Aperture 0.4) providing a focal spot of $\approx 10 \mu \mathrm{m}$ extent. The SHG signal is a backreflected signal, redirected back through the same lens, through a beam splitter, and into a photomultiplier tube and depends critically on the position of the focal volume with respect to the various layers sampled. The corroded samples consisted of blocks of iron exposed to open air. The uncorroded sample was hand polished. A 30- $\mu \mathrm{m}$ thick layer of paint was painted onto one corroded and the uncorroded sample. Of the painted, rusted, and metallic iron samples, the surface paint layer generated the largest SHG signals and the metallic iron generated the least. By using signal contrast and a computerized motor translation stage to control the lateral and longitudinal position of the focused laser spot, a 2D/3D map of the system profile could be generated. However, the paint transmission characteristic was only $0.09 \%$ within the spectral range of $400-800 \mathrm{~nm}$. The scientists suggest adapting different light sources for different types of coating in order to maximize transmission to the underlayers. This work provides a new means of early corrosion detection for aircraft, structures, and other industrial equipment.

JUNE LAU

\section{Electrochemical Reduction in Alkaline Electrolyte Removes CuS Phase to Form CulnS ${ }_{2}$-Based Solar Cells}

A team of researchers in the Solar Energetics division of the Hahn-MeitnerInstitute (HMI) in Berlin, Germany, has reported a method for the removal of unwanted $\mathrm{CuS}$ from the surface of $\mathrm{CuInS}_{2}$-based photovoltaic cells. Instead of the traditional cyanide washing, a straightforward electrochemical reduction in an alkaline electrolyte and subsequent dissolution are employed, leading to complete removal of the covellite (CuS) phase and a photoactive $\mathrm{CuInS}_{2}$ material.
Thin film solar cells based on $\mathrm{CuInS}_{2}$ are promising materials for large-scale applications, as they show high performance at low production costs. $\mathrm{CuInS}_{2}$ has a high absorption coefficient and a bandgap energy around the maximum of the solar spectrum. "However, there are several problems that hinder the further development", said H.J. Lewerenz, professor at the HMI. "A cyanide etch is used to remove the unwanted covellite phase from the surface, a poisonous CdS layer is implemented and this results in a band II lineup leading to reduced photovoltages."

As reported in the September issue of Electrochemical and Solid-State Letters, the films are prepared by sequential sputtering of the metals with a copper-to-indium ratio larger than one and subsequent annealing in a sulfur atmosphere. During the annealing process, $\mathrm{CuS}$, which is a $p^{+}$-type semiconductor, is formed on the surface of the grains and needs to be removed. The only process that selectively attacks the CuS while leaving the $\mathrm{CuInS}_{2}$ intact is a cyanide etch.

"We have now found a possibility to clean the grain surfaces from CuS without using a cyanide solution," said U. Störkel, who is working on a postdoctorate with Lewerenz. "The disappearance of CuSrelated features in cyclic voltammograms recorded in $0.1 \mathrm{M} \mathrm{K}_{2} \mathrm{SO}_{4}$ at $\mathrm{pH} 10$ suggested that the covellite phase might dissolve during electrochemical cycling in alkaline $\mathrm{K}_{2} \mathrm{SO}_{4}$ solution at potentials between -0.9 and $-1.2 \mathrm{~V}$ versus saturated calomel electrode or SCE." The current versus time behavior at fixed potentials in this range showed that the number of charges that had flown was proportional to the excess of $\mathrm{Cu}$ used in the preparation of the films. $\mathrm{X}$-ray diffraction confirmed the complete removal of the covellite phase and gave evidence for the formation of small amounts of $\mathrm{Cu}_{2-\delta} \mathrm{S}$. Scanning electron micrographs before and after cycling demonstrated the removal of most surface species from the polycrystalline $\mathrm{CuInS}_{2}$.

"We believe that the CuS is reduced starting at about $-0.9 \mathrm{~V}$," said M. Aggour, a senior lecturer at the University Mohammed V in Rabat, Morocco, and regular visiting scientist at the HMI. " $\mathrm{Cu}_{2} \mathrm{~S}$ can exchange anions with the solution resulting in surface bound $\mathrm{Cu}(\mathrm{I})(\mathrm{OH})_{\mathrm{s}}$. These species can undergo a redox reaction with water to form water soluble $\mathrm{Cu}(\mathrm{OH})_{2}$ and hydrogen. The gas evolution is visible to the naked eye even at $-0.95 \mathrm{~V} . "$

His collaborator, Joachim Klaer, said, "It is, of course, also possible that partially reduced copper species or copper metal are formed. We saw small amounts of $\mathrm{Cu}_{2-\delta} \mathrm{S}$ in the XRD [x-ray diffraction] 
patterns. There are no copper peaks visible, but we cannot exclude the presence of a small amount. That is the reason for our planned synchrotron experimentsthe high energy resolution will allow us to distinguish $\mathrm{Cu}^{0}, \mathrm{Cu}^{+}$, and $\mathrm{Cu}^{2+}$ easily."

The electrochemically treated materials show significant photocurrent starting at $-0.49 \mathrm{~V}$ during scans toward more negative potentials and up to $-0.32 \mathrm{~V}$ in the backwards scans. The photocurrent is smaller than that of KCN-etched samples. "This might be due to the presence of a thin $\mathrm{Cu}_{2-\delta} \mathrm{S}$ layer or residual copper," said Störkel. "We are currently working on the transformation of $\mathrm{Cu}_{2} \mathrm{~S}$ into stoichiometric $\mathrm{CuInS}_{2}$ using, for example, alkaline solutions containing $\operatorname{In}^{3+}$ ions."

\section{CORA LIND}

\section{Third-Body Interfacial Layers Reduce Wear of Dental Glass-Ceramic Surfaces}

An understanding of the mechanisms of wear between restorative dental glassceramic interfaces is important in the development of new, wear-resistant dental materials. Ideally, experiments should simulate the conditions inside the mouth during chewing, where debris layers formed between the teeth are flushed away by saliva and the sliding motion of the contacting surfaces, preventing the formation of a stable, third-body interface. Researchers Attota Ravikiran and Said Jahanmir of the Ceramics Division of the National Institute of Standards and Technology (NIST) compared the wear of surfaces that were continually flushed with fresh distilled water with those whose surfaces were not flushed during controlled grinding to elucidate the nature and importance of the third-body interface. Their results are reported in the July issue of the Journal of the American Ceramic Society.

Blocks of Dicor MGC (from Dentsply), a tetrasilicic fluoromica compound containing mica platelets with an average diameter of $2 \mu \mathrm{m}$, were polished to an average surface roughness of $5.6 \pm 1.2 \mathrm{~nm}$ using diamond pastes. High-purity $(99.5 \%)$ alumina balls with a Vickers hardness of $14.7 \mathrm{GPa}$ were fashioned into a pin-on-disk type of tribometer. The alumina balls were ground against the polished faces of the Dicor MGC at loads varying from 5 to $30 \mathrm{~N}$ along wear-track diameters of 6.5 and $9.5 \mathrm{~mm}$, with the contact surface submerged in distilled water at all times. In one set of tests (the "flushing" experiments), the contact surface was continuously flushed with fresh distilled water during the entire sliding period; in the "nonflushing" experiments, the original water was retained throughout the experiment, so that the surfaces were not cleaned of debris.

Subsequent measurement of wear volumes revealed that the flushed surfaces wore more heavily than the nonflushed surfaces. This result indicates that accumulation of third-body wear debris at the interface of dental ceramics acts as a protective, load-carrying film that separates the primary contact surfaces and thus reduces wear. In the absence of such an accumulation-when the interface is flushed-the dental ceramic itself is subject to greater degrees of deformation and fracture. The researchers suggest that experiments utilizing a flushing technique simulate actual oral conditions more closely, and might give more meaningful data in future investigations.

TIM PALUCKA

\section{Sputtered Co/Ti Film Directly Oxidized Forms High- $\kappa \mathrm{CoTiO}_{3}$}

A high-quality, ultrathin, high- $\kappa$ cobalttitanium oxide $\left(\mathrm{CoTiO}_{3}\right)$ dielectric was recently reported in the September issue

\section{Cost-Effective Portable Spin Coaters}

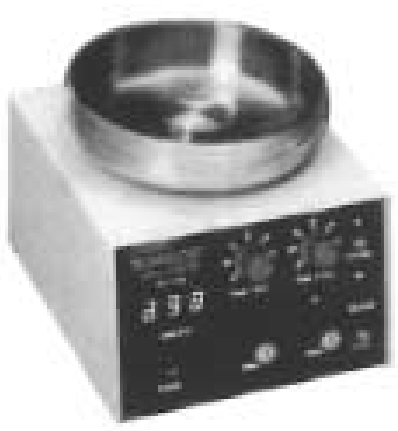

Two-Stage Spinning

- Dispense liquid during Stage 1

- Spin-up and flatten during Stage 2

Adjustable Speed

Stage 1

- 500 to $2,500 \mathrm{rpm}$

- 2 to 18 seconds

Stage 2

- 1,000 to $8,000 \mathrm{rpm}$

- 3 to 60 seconds

\section{Precision Dip Goaters}

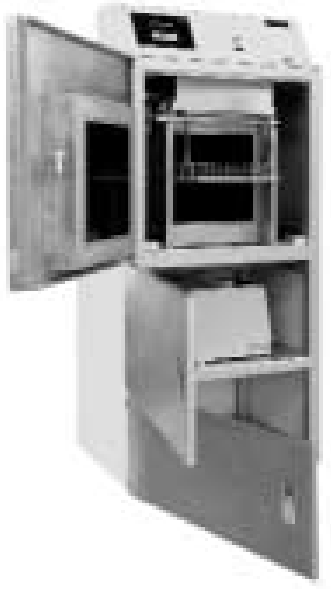

Robust Laboratory Coater

- Easy to operate

- Speed range of 0 to $30 \mathrm{~cm}$ per minute

- Adjustable travel span

- Controllable atmosphere

- Curing chamber

- Custom fabrication

\section{Coating Solutions}

- Available for metal oxides, nitrides and carbides

Distributorships Available

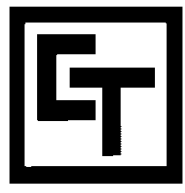
CHEMAT TECHNOLOGY, INC.

9036 Winnetka Avenue, Northridge, CA 91324

U.S. Toll-Free 800-475-3628 • Non-U.S. 818-727-9786

Fax: 818-727-9477 • E-mail: chemat@aol.com

www.chemat.com

Circle No. 4 on Inside Back Cover 